Hanna Kastner, Ulrike Einhorn-Stoll, Alexandra Fatouros, Stephan Drusch

\title{
Impact of sodium ions on material properties, gelation and storage stability of citrus pectin
}

Journal article | Accepted manuscript (Postprint)

This version is available at https://doi.org/10.14279/depositonce-9771

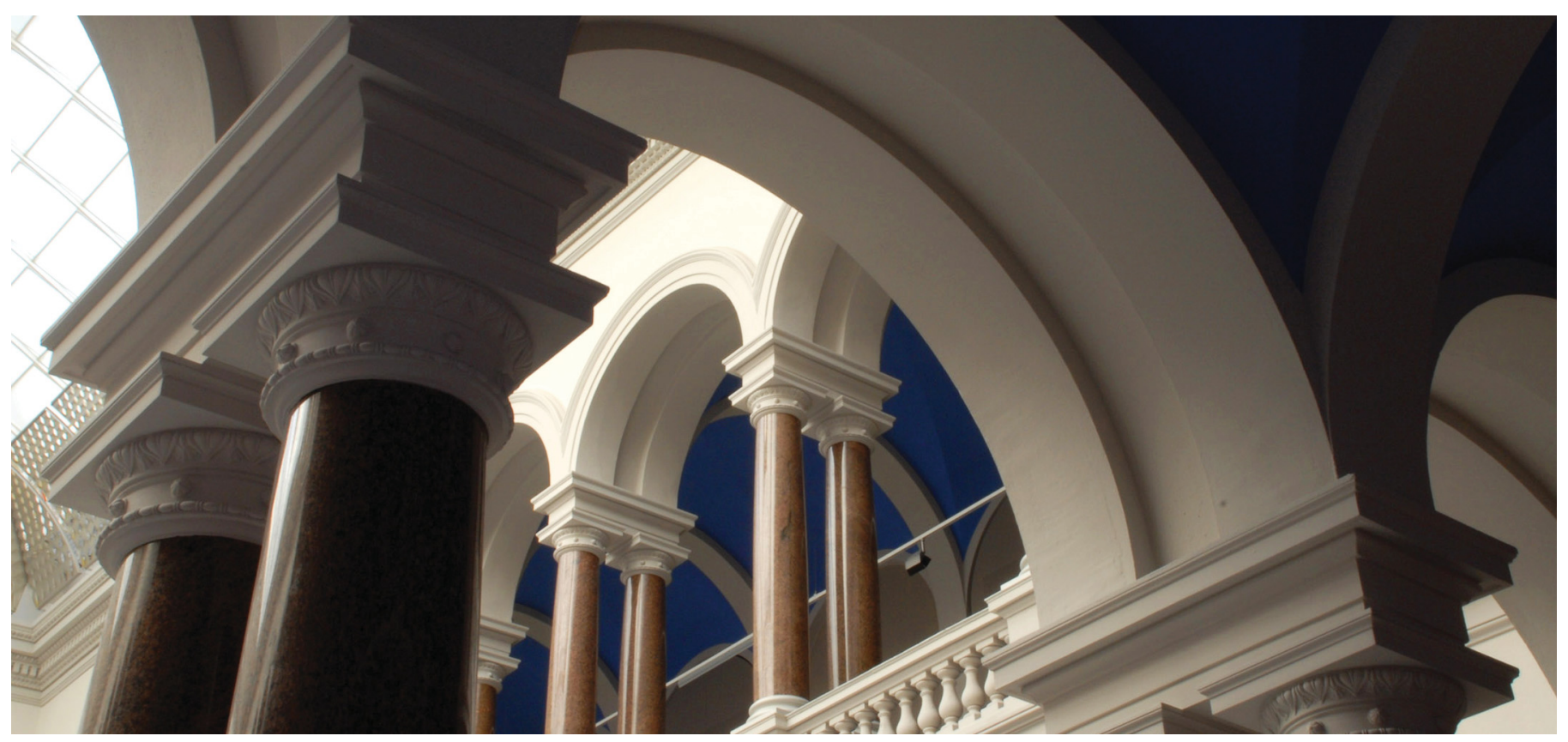

Kastner, H., Einhorn-Stoll, U., Fatouros, A., \& Drusch, S. (2020). Impact of sodium ions on material properties, gelation and storage stability of citrus pectin. Food Hydrocolloids, 104, 105750. https://doi.org/10.1016/j.foodhyd.2020.105750 
Impact of sodium ions on material properties, gelation and storage stability of citrus pectin

\author{
Hanna Kastner ${ }^{1}$, Ulrike Einhorn-Stoll ${ }^{1}$, Alexandra Fatouros ${ }^{2}$ and Stephan Drusch ${ }^{1}$ \\ ${ }^{1}$ Department of Food Technology and Food Material Science, Technische Universität Berlin, Königin- \\ Luise-Straße 22, 14195 Berlin, Germany \\ ${ }^{2}$ Department of Food Chemistry and Analytics, Technische Universität Berlin, Gustav-Meyer-Allee \\ 25, 13355 Berlin, Germany
}

\title{
Abstract
}

Material properties, gelation and storage stability of demethoxylated pectin samples strongly varied in dependence on the applied modification method. It was assumed that the content of sodium ions and their resulting electrostatic interactions with free carboxyl groups were crucial for these differences. Sodium ions were widely removed by acidic modification but added during alkaline and enzymatic modification using $\mathrm{NaOH}$ in a $\mathrm{pH}$-stat method. It was the aim of the present study to investigate the individual impact of sodium ions on pectin properties using samples with similar molecular parameters but different sodium ion content.

Sodium enrichment of pectin increased the pectin particle surface and, as a consequence, the pectinwater-interactions. Differences in molecular structure and material properties were reflected in simultaneous thermal analysis; an exothermic starting peak in DSC vanished and pectin pyrolysis was accelerated after sodium ion enrichment. Gel formation was affected by sodium ions. It was delayed in a sugar-acid system by reducing the number of hydrogen bonds and accelerated in a sugar-calcium system by reducing electrostatic repulsion. Sodium ions increased the storage stability of pectin. They were bound to free carboxyl groups (-COONa) and restricted degradation reactions during storage which required these groups, in particular depolymerisation by decarboxylation. 


\section{Introduction}

Pectin is a frequently used thickening and gelling agent in several food and non-food applications with high consumer acceptance. It consists of a backbone of galacturonic acid (homogalacturonan) in combination with rhamnose (rhamnogalacturonan) and side chains of neutral sugars as described in detail by many authors (Voragen, Coenen, Verhoef, \& Schols, 2009; Endress \& Christensen, 2009; Thakur, Singh, \& Handa, 1997). The properties of commercial pectin vary in dependence on the botanical origin (mainly citrus peel and apple pomace), climate conditions and extraction procedure. Citrus and apple pectin have a high degree of methoxylation (DM) of the galacturonic acid. The wide range of applications requires tailored pectin properties, which are achieved by modification procedures during or after pectin extraction by demethoxylation or amidation (Rolin, Chrestensen, Hansen, Staunstrup, \& Sørensen, 2010). Chemical demethoxylation under acidic or alkaline conditions results in a random pattern of the newly formed free carboxyl groups, and so do most of the enzymatic procedures using fungal pectinmethylesterases (fPME). In contrast, pectinmethylesterases of plant origin (pPME) cause a block-wise pattern of the free carboxyl groups. Chemical demethoxylation in the presence of ammonium ions results in low-methoxylated amidated pectin (Lopes da Silva \& Rao, 2006).

- Apart from the intended alterations, unintended side effects during modification occur (Garnier, Axelos, \& Thibault, 1993), and samples with similar degree of methoxylation (DM) may thus behave differently. Previous studies of our group on citrus pectin revealed that the material properties, gelation and storage stability of pectin samples varied strongly in dependence on the preparation conditions during chemical demethoxylation under acidic or alkaline conditions as well as during enzymatic demethoxylation:

- Particle properties of pectin powder are crucial for pectin-water interactions and for dissolution prior to application. The particle form, size and structure of differently modified samples varied considerably. Particles were large, compact and mainly smooth after demethoxylation under acidic conditions at $\mathrm{pH} 1.5$, whereas the particles of pectin demethoxylated under alkaline conditions at $\mathrm{pH} 11$ were smaller, fibrous and had a rougher surface. Samples from acidic demethoxylation had a lower BET-surface than alkaline modified samples or than samples prepared using PME at pH 4.4 (fPME) or 7.4 (pPME). As a consequence, also their water uptake by sorption varied (Einhorn-Stoll, Hatakeyama, \& Hatakeyama, 2012; Einhorn-Stoll \& Kunzek, 2009).

- The gelation of acidic and enzymatically modified pectin samples varied in sugar-acid as well as in sugar-calcium systems (Kastner, Einhorn-Stoll, \& Drusch, 2019). Gelation of enzymatically modified pectin started at higher temperature than gelation of acidic modified pectin, and the corresponding gels were more elastic and less viscous after cooling. The difference was more pronounced for pectin demethoxylated by pPME than for those modified by fPME. 
- The stability of alkaline modified pectin during storage in a climate chamber was higher than that of acidic modified pectin with similar DM and intrinsic viscosity. Thermal degradation of the former by demethoxylation and, in particular, by depolymerisation was lower (Einhorn-Stoll, Kastner, Urbisch, Kroh, \& Drusch, 2019).

It was assumed that the presence of monovalent cations contributes to these differences. Sodium and potassium ions are naturally present in pectin, but are widely removed during demethoxylation under acidic conditions due to washing and precipitation (Einhorn-Stoll et al., 2012). In contrast, sodium ions are added during alkaline or enzymatic modification when using $\mathrm{NaOH}$ for keeping the pH constant (Kastner et al., 2019; Einhorn-Stoll et al., 2019; Hotchkiss et al., 2002). Interactions of pectin with monovalent cations have been studied mainly in solution and with respect to gel formation. They may be specific or non-specific and contribute to hydration. Ions may form a "layer" around macromolecules and effect several functional properties such as water sorption, dissolution, solubility or gelation (Gao et al., 2017). The interactions of pectin and monovalent cations in solution strongly depend on $\mathrm{pH}$ and $\mathrm{DM}$ of the pectin. The $\mathrm{pK}_{\mathrm{a}}$ of citrus pectin, at which $50 \%$ of the free carboxyl groups are dissociated, is about 3.5 (Ralet, Dronnet, Buchholt, \& Thibault, 2001). Thus, the lower the DM and the higher the $\mathrm{pH}$, the more dissociated carboxyl groups are available and the more electrostatic interactions with cations are possible.

The presence of monovalent cations in pectin solutions prior to drying had an impact also on the quality of pectin films (Kalathaki, Alba, Muhamedsalih, \& Kontogiorgos, 2019) and on the pectin-water interactions after drying (Einhorn-Stoll et al., 2012). Sodium ions, bound to hydrocolloids, interact with water (Kalathaki et al., 2019; Deshpande, Scheicher, Ahuja, \& Pandey, 2008) and may reduce demethoxylation during storage in a low-moisture environment by reducing the available water. Moreover, in presence of sodium ions depolymerisation is limited as a result of the reduction of demethoxylation and accessibility of free carboxyl groups (Einhorn-Stoll et al., 2019).

Cations also play a crucial role in pectin gelation. There are two general gelation mechanisms, coldset and ionotropic gelation. Cold-set gelation, typical for the gelation of high-methoxylated pectin with $\mathrm{DM}>50 \%$, is a two-phase process with a threshold around $50^{\circ} \mathrm{C}$. Above this temperature, the first dominating junction zones are formed by hydrophobic interactions between ester groups, below $50{ }^{\circ} \mathrm{C}$ they are replaced by hydrogen bonds between free carboxyl groups (Lopes da Silva \& Rao, 2006; Thakur et al., 1997; Oakenfull \& Scott, 1984). Ionotropic gelation occurs in addition to cold-set gelation mainly in low-methoxylated pectin (LMP). Added calcium or other divalent cations bind to blocks of dissociated free carboxyl groups and form bridges between two pectin molecules (Fraeye, Duvetter, Doungla, Van Loey, \& Hendrickx, 2010; Luzio \& Cameron, 2008; Vincent \& Williams, 2009; Liners, Thibault, \& Van Cutsem, 1992; Powell, Morris, Gidley, \& Rees, 1982). Presence of sodium ions most likely affected pectin gelation in a sugar-acid as well as sugar-calcium pectin system in a recent work of our group (Kastner et al., 2019), and this was also reported in other studies. In pectin with 
$\mathrm{DM}<65 \%$, monovalent cations supported cold-set gelation by reducing electrostatic repulsion (Wehr, Menzies, \& Blamey, 2004; Ström, Schuster, \& Goh, 2014). Unexpectedly, gelation in the presence of sodium and potassium ions was observed during enzymatic pectin demethoxylation (Yoo et al., 2009) or after addition sodium salts to a pectin solution under acidic (Wang, Hua, Yang, Kang, \& Zhang, 2014) as well as alkaline conditions (Wang et al., 2019). Monovalent cations may have an impact on ionotropic pectin gelation by mixed counter ion interactions and competitive ion binding (Lips, Clark, Cutler, \& Durand, 1991; Rees, 1982). As a consequence, less calcium would be required for gel formation (Garnier et al., 1993; Axelos \& Thibault, 1991). Sodium ions are also able to replace calcium ions and to alter the structure of pectin (Morris, Powell, Gidley, \& Rees, 1982) and к-carrageenan (Evageliou, Ryan, \& Morris, 2019) gels. In addition, a presence of sodium ions may affect the elasticity and thermoreversibility of sugar-calcium gel prepared from amidated pectin (Marudova \& Jilov, 2003). In the majority of these studies, pectin also differed with respect to other parameters (e.g. DM, molecular weight).

Though a general association of monovalent cations and pectin material properties, gelation and storage stability must be assumed and was also part of the conclusion from our previous studies, experimental evidence is still lacking. The tested samples differed not only in their content of monovalent cations but also in other parameters, like neutral sugar content and the molecular weight. Both parameters undergo changes depending on the demethoxylation method (Einhorn-Stoll et al., 2019; Kastner et al., 2019). It is well described that gelation is affected by neutral sugar side chains (Sousa, Nielsen, Armagan, Larsen, \& Sørensen, 2015) and by the molecular weight (Ngouémazong et al., 2012; Hotchkiss et al., 2002). Furthermore, cleavage of neutral sugar side chains during storage competes for water with demethoxylation and backbone hydrolysis and may affect thermal degradation type and intensity.

Aim of the present work was to prepare pectin samples with different content of sodium ions but similar molecular characteristics in order to investigate the impact of monovalent cations on pectin material properties, gelation and storage stability. Therefore, a sodium-depleted pectin was dissolved, and one half was immediately re-precipitated while the other half was "loaded" with sodium ions by rapid addition of $\mathrm{NaOH}$ at low temperature. Sodium ion content was analysed by flame photometry. Material properties were investigated by scanning electron microscopy (SEM) and measurement of BET-surface as well as water uptake by sorption. Gelation was studied using oscillation rheology in a sugar-acid as well as sugar-calcium system. Stability against demethoxylation and depolymerisation during storage was examined in a climate chamber at $60{ }^{\circ} \mathrm{C}$ and $80 \%$ relative humidity. The course and intensity of the degradation reactions was monitored by spectroscopic methods, thermal analysis, gel permeation chromatography (GPC) and colour measurements. 


\section{Materials and methods}

\subsection{Preparation of pectin samples}

A high-methoxylated commercial citrus pectin with DM 71\%, kindly provided by Herbstreith \& Fox KG (Neuenbürg, Germany), was demethoxylated in acidic environment. Pectin was dissolved in $1 \mathrm{M}$ hydrochloric acid solution (1.5\% w/w) and kept for $38 \mathrm{~h}$ at room temperature. Afterwards pectin was precipitated by adding the threefold volume of $95 \mathrm{vol} \%$ ethanol. The precipitate was washed at least five times with 95 vol\% ethanol, coarsely ground, dried at $50{ }^{\circ} \mathrm{C}$ and milled (ZM1 with $250 \mu \mathrm{m}$ sieve, Retsch, Haan, Germany). Acidic modification resulted in a pectin (AMP) with DM $43.1 \%$ and intrinsic viscosity of $594 \mathrm{~cm}^{3} \mathrm{~g}^{-1}$. For sodium-enrichment, the pectin was dissolved in distilled water $(1.5 \% \mathrm{w} / \mathrm{w})$ and further modified as shown in Fig. 1. Half the solution was immediately precipitated with the threefold volume of 95 vol\% ethanol and treated as described above for AMP. This sample was named as sodium-depleted low-methoxylated pectin LMP. The other half of the solution was "loaded" with sodium ions by adjusting the $\mathrm{pH}$ to 11.0 using $0.5 \mathrm{M} \mathrm{NaOH}$ within 5 minutes at $5^{\circ} \mathrm{C}$. The $\mathrm{pH}$ was immediately lowered to 2.5 by adding $10 \% \mathrm{v} / \mathrm{v}$ hydrochloric acid. Subsequent treatment was carried out as described for LMP, but additionally washing steps with 95 vol\% ethanol were performed until the sample was free from chloride ions (negative silver nitrate test). This low-methoxylated sodiumenriched sample was named as $\mathrm{LMP}+\mathrm{Na}$. The samples were stored at $-10^{\circ} \mathrm{C}$ until further use. All chemicals used in the study were of analytical grade.

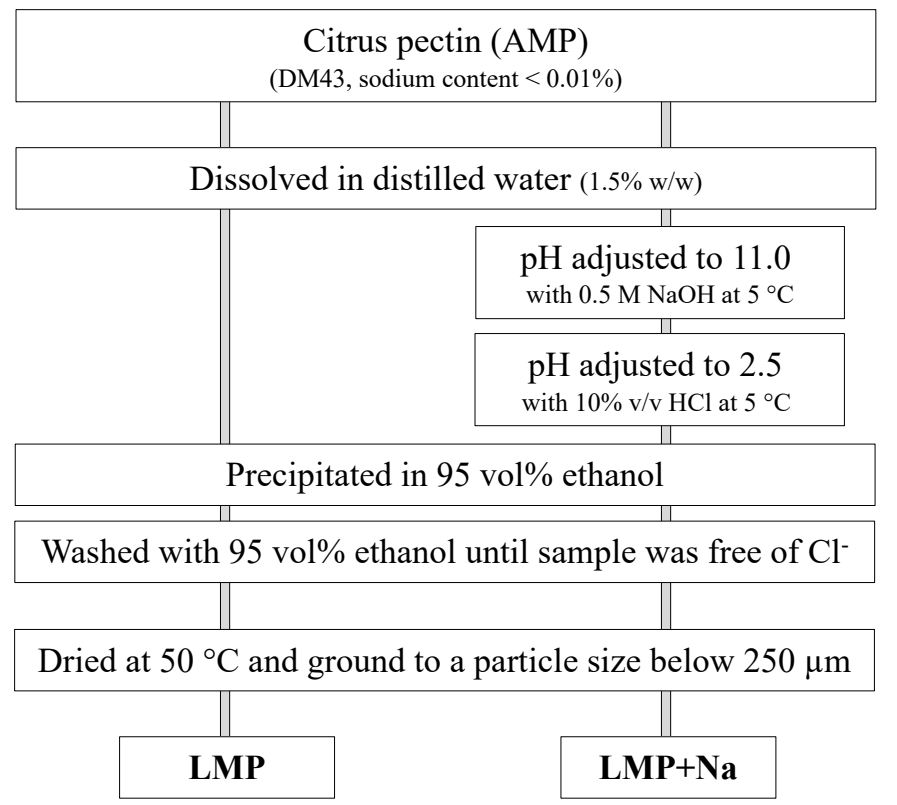

Fig. 1 Preparation of the sodium-depleted (LMP) and sodium-enriched (LMP+Na) pectin sample. 


\subsection{Analysis of molecular parameters and chemical alterations}

The DM was determined in duplicate using the chromotropic acid method (Bäuerle, Otterbach, Gierschner \& Baumann, 1977). The intrinsic viscosity ([ $\eta])$ was analysed in duplicate at $20{ }^{\circ} \mathrm{C}$ by using the rolling ball micro viscometer LOVIS 2000M (Anton Paar GmbH, Ostfildern-Scharnhausen, Germany) with a $1.59 \mathrm{~mm}$ capillary and a steel ball $(\mathrm{d}=1.5 \mathrm{~mm})$ as described by Kastner et al. (2019). Gel permeation chromatography (GPC) was applied for examination of the molecular weight distribution, based on the size calibration with pullulan reference substances of different molecular weight (1, 5, 20, 100 and 400 kDa; PSS-pulkit, PSS Polymer Standards Service GmbH, Mainz, Germany) as described before (Wegener, Kaufmann, \& Kroh, 2017).

The sodium ion content was examined from the ash by flame atomic absorption spectrometer AAnalyst $^{\mathrm{TM}} 800$ (PerkinElmer, Rodgau, Germany; acetylene/air gas mixture). All determinations were performed in duplicate. Unsaturated uronides, which were formed during thermal degradation by depolymerisation by ß-elimination and decarboxylation, were determined by measuring the absorption at $235 \mathrm{~nm}$ in a solution of $0.2 \%$ pectin in distilled water using a Ultrospec ${ }^{\mathrm{TM}} 1100$ pro UV/visible spectrophotometer (Amersham Biosciences, Freiburg, Germany). For complete dissolution, the samples were stirred for $24 \mathrm{~h}$ at room temperature. They were filtered through a micro filter $(1 \mu \mathrm{m}$ pore size) in order to remove possible impurities.

Finally, ATR-FTIR measurements were performed using a portable Bruker Alpha 1 with a Platinum ATR single reflection diamond (Bruker Optik $\mathrm{GmbH}$, Ettlingen, Germany). Sample spectra were recorded between 400 and $4000 \mathrm{~cm}^{-1}$ without further sample preparation using attenuated total reflection (ATR) with a spectral resolution of $4 \mathrm{~cm}^{-1}$ at room temperature. All spectra were composed of 32 scans. Background spectra were recorded for each measurement and subtraction was performed for all spectra using OPUS 7.2 software (Bruker Optik $\mathrm{GmbH}$, Ettlingen, Germany). The standard pressing mechanism of the instrument allowed a constant pressure for all measurements. Signals in the "finger-print" region below $1000 \mathrm{~cm}^{-1}$ are not assignable to specific functional groups or types of bonds, but give specific information about individual polysaccharides in the backbone as well as in side chains of pectic polysaccharides (Kačuráková, Capek, Sasinková, Wellner, \& Ebringerová, 2000; Coimbra, Barros, Rutledge, \& Delgadillo, 1999; Coimbra, Barros, Barros, Rutledge, \& Delgadillo, 1998).

\subsection{Characterisation of pectin material properties}

Scanning electron microscopy (SEM) of the dried pectin samples was used to qualitatively describe differences in the particle properties such as size, form and surface, it was performed at the Centre for Electron Microscopy (ZELMI) of the Technische Universität Berlin using a S-2700 scanning electron microscope (Hitachi, Tokyo, Japan) after sputtering the samples with gold. BET-surface was 
measured in duplicate using a surface area analyser QUADRASORB ${ }^{\mathrm{TM}}$ SI Surface Area and Pore Size Analyzer (Quantachrome Instruments, Boynton Beach, USA) with nitrogen as adsorptive agent and a relative pressure up to 0.25 .

For colour determination, dry samples were examined with a Chromameter CR 300 (Minolta, Osaka, Japan) using the CIELAB system (10 measurements per sample). Simultaneous thermal analysis (STA), a combination of differential scanning calorimetry (DSC) and thermogravimetry (TG), properly reflects the alteration of material properties after enriching the samples with sodium ions, as well as the intensity of thermal degradation (thermolysis) during storage. It was performed using the STA 449 F3 Jupiter (Netzsch, Selb, Germany), an inert helium atmosphere $(70 \mathrm{~mL} / \mathrm{min})$, linear heating rate 10 $\mathrm{K} / \mathrm{min}$ from 20 to $450{ }^{\circ} \mathrm{C}$ in $85 \mu \mathrm{L} \mathrm{Pt}$ open crucible, and sample weight of approximately $20 \mathrm{mg}$. The DTG-curve was calculated as first derivation of the TG-signal. The instrument was calibrated by a standard procedure. Measurements were performed in duplicate. Water uptake by sorption was determined using a gravimetric method as described in detail before (Einhorn-Stoll, Vasileva, Hecht, \& Drusch, 2016). In brief, the pectin was spread on a petri dish, stored in a desiccator with water at $30{ }^{\circ} \mathrm{C}$ for $24 \mathrm{~h}$ and the weight difference was determined in triplicate.

\subsection{Pectin gelation - Rheological properties and structuring parameters}

The gelation was analysed in triplicate in a sugar-acid as well as sugar-calcium system, based on the industrial standard methods of IFT Committee (1959) and described before in Kastner et al. (2019). Sugar-acid gels were prepared as follows: $2.75 \mathrm{~g}$ pectin $(0.27 \mathrm{wt} . \%)$ were dissolved in $430 \mathrm{~g}$ distilled water, $647.3 \mathrm{~g}$ sucrose were added, and the total mass was reduced to $1020 \mathrm{~g}$ by boiling. Subsequently, $7 \mathrm{~mL}$ of $48.8 \% \mathrm{w} / \mathrm{v}$ tartaric acid solution were added. The final $\mathrm{pH}$ of solution was 2.2 and the total solids was $65 \mathrm{wt} . \%$. Sugar-calcium gels were prepared by dissolving $6 \mathrm{~g}$ pectin (0.67 wt.\%) and $264 \mathrm{~g}$ sucrose in $637.5 \mathrm{~g}$ distilled water. $7.5 \mathrm{~mL} 54.3 \% \mathrm{w} / \mathrm{v}$ citric acid solution, $15 \mathrm{~mL}$ $6 \% \mathrm{w} / \mathrm{v}$ sodium citrate solution and $37.5 \mathrm{~mL} 2.205 \% \mathrm{w} / \mathrm{v} \mathrm{CaCl}_{2}$ solution were added. The total mass was reduced by boiling to $900 \mathrm{~g}$. The final solution had a pH of 2.8 and a content of total solids of approximately $32 \mathrm{wt} . \%$. The total solids content for both systems was determined using an automatic digital refractometer AR200 (Reichert GmbH, Seefeld, Germany).

Oscillation measurements were performed in order to characterize the viscoelastic behaviour of the samples during cooling using a rheometer (Physica MCR 301, Anton Paar, Ostfildern, Germany), equipped with a profiled rotational cylinder. Starting from $105^{\circ} \mathrm{C}$ for sugar-acid and $100{ }^{\circ} \mathrm{C}$ for sugarcalcium system, respectively, the samples were cooled to $10^{\circ} \mathrm{C}$ with a cooling rate of $1 \mathrm{~K} / \mathrm{min}$. Storage modulus $\left(G^{\prime}\right)$ and loss modulus $\left(G^{\prime \prime}\right)$ were recorded at a frequency of $1 \mathrm{~Hz}$ and a strain of $10^{-3}$. The structuring parameters were calculated as suggested by Kastner, Einhorn-Stoll, \& Senge (2012). The gel point (GP) was determined as the cross-over of $G^{\prime}$ and $G^{\prime \prime}\left(G^{\prime \prime} / G^{\prime}=1\right)$. The initial (IST) and critical (CST) structuring temperature were calculated from the first derivation of $\mathrm{dG}^{\prime} / \mathrm{dt}$, the 
structuring velocity curve, using OriginPro9.6 software (OriginLab Corp., Northampton, USA). IST is the temperature, at which the value $\mathrm{dG}^{\prime} / \mathrm{dt}$ differed from zero for the first time, and CST is the extrapolated temperature of the first strong increase of $\mathrm{dG}^{\prime} / \mathrm{dt}$. The presented structuring velocity curves were the average of 3 measurements.

\subsection{Pectin storage stability}

All samples were stored in Petri dishes, with a spacer holding the lid slightly open, in a climate chamber with controlled humidity (KBF 115, Binder, Tuttlingen, Germany) at $60{ }^{\circ} \mathrm{C}$ and $80 \%$ relative humidity for four weeks. The layer of each sample was about $1 \mathrm{~cm}$ high. Samples were taken after 7 , 14, 21 and 28 days, dried at room temperature in a desiccator for $24 \mathrm{~h}$ in order to remove absorbed water, and stored at $-10^{\circ} \mathrm{C}$.

\section{Results and discussion}

The sodium-enriched sample LMP+Na had a sodium ion content of $1.16 \%$, while the sodium-depleted sample LMP contained $0.01 \%$. The successful binding of the sodium ions to the pectin structure is detected by ATR-FTIR (Fig. 2a). The protonated carboxyl group - $\mathrm{COOH}$ and the ionic carboxylate group -COONa are characterized by different signals. The former shows a maximum at about $1730 \mathrm{~cm}^{-1}$, overlaid with the absorption band of methoxyl ester group, whereas the latter shows maxima at about $1650-1630 \mathrm{~cm}^{-1}$ (COO- asymmetric stretch) and at $1410 \mathrm{~cm}^{-1}$ (COO- symmetric stretch) as described in several studies (Fellah, Anjukandi, Waterland, \& Williams, 2009; Manrique \& Lajolo, 2002; Chatjigakis et al., 1998). Enriching with sodium ions strengthened the carboxylate signal and shifted its maximum to about $1630 \mathrm{~cm}^{-1}$. Comparable values for this signal are described also by other references (Chylinska, Szymanska-Chargot, \& Zdunek, 2016, Coimbra et al., 1999), the signal maximum may partly depend on residual water in the sample. Similar differences with respect to the carboxylate signal were also found in a corresponding paper (Einhorn-Stoll et al., 2020), comparing acidic and alkaline demethoxylated pectin (alkaline demethoxylation was performed using $0.5 \mathrm{M}$ $\mathrm{NaOH}$ ). The signal at $1730 \mathrm{~cm}^{-1}$ was nearly unchanged after sodium ion loading, probably due to the overlay of the carboxyl groups and the methoxyl group signals and the nearly constant DM (LMP+Na: $41.4 \pm 0.8 \%$ and LMP: $42.8 \pm 0.1 \%)$. 

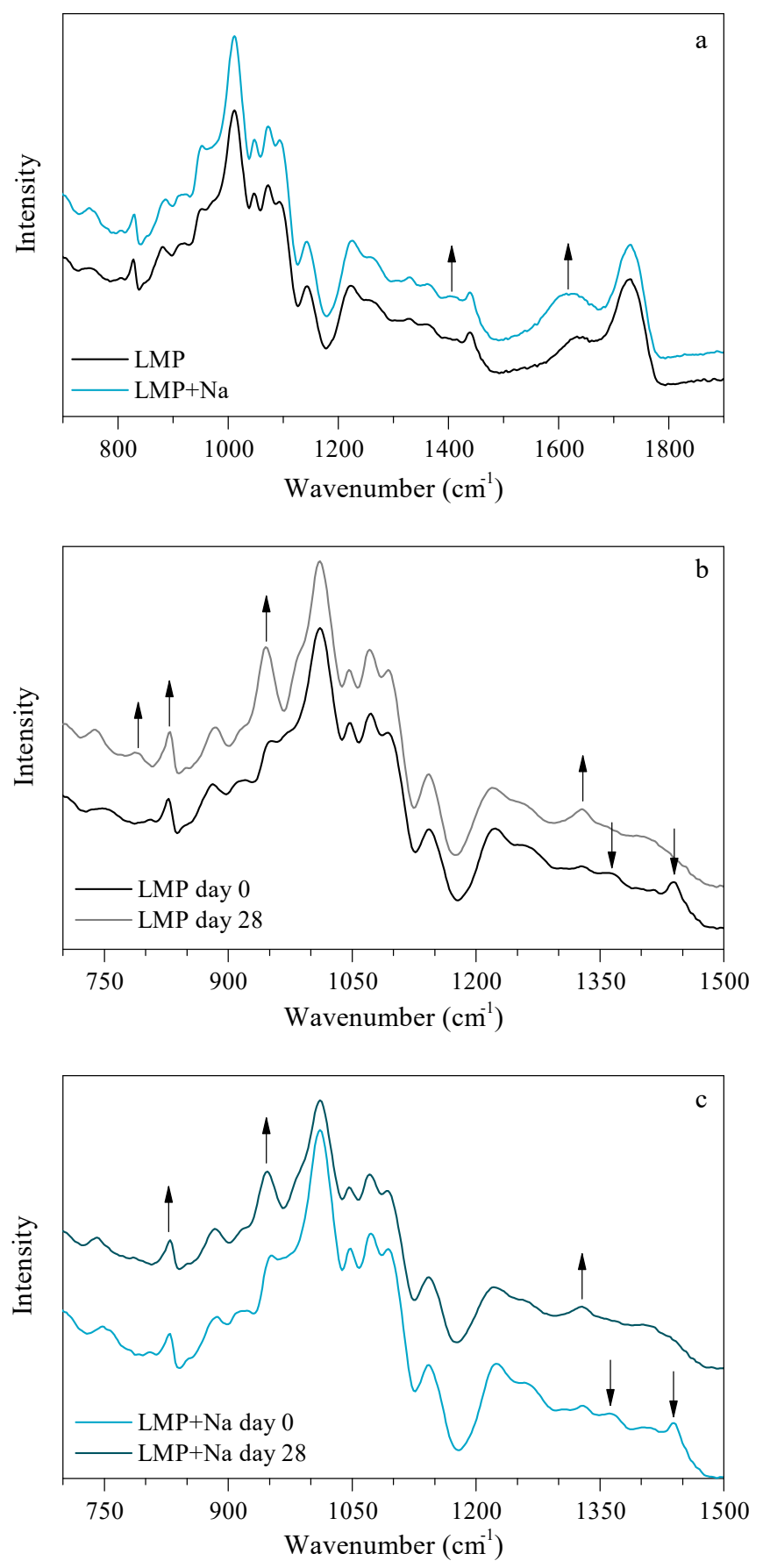

Fig. 2 ATR-FTIR spectra of the pectin samples before (day 0) and after (day 28) thermolysis. a: Comparison of the unstored (day 0) sodium-enriched (LMP+Na) and sodium-depleted (LMP) samples. b: Thermal degradation of $L M P$, after storage for 28 days, at $60{ }^{\circ} \mathrm{C}$ and $80 \%$ relative humidity. C: Influence of sodium ions (LMP $\left.+\mathrm{Na}\right)$ on thermal degradation, after storage for 28 days, at $60{ }^{\circ} \mathrm{C}$ and $80 \%$ relative humidity.

Intrinsic viscosity (LMP+Na: $519 \pm 3.1 \mathrm{~cm}^{3} \mathrm{~g}^{-1}$ and LMP: $\left.512 \pm 4.9 \mathrm{~cm}^{3} \mathrm{~g}^{-1}\right)$ and molecular weight distribution (Fig. 3, samples day 0 ) as well as the other signals in the fingerprint-region of the ATRFTIR spectra between 700 and $1500 \mathrm{~cm}^{-1}$ (Fig. 2a) did not differ between samples. Thus, the two 
samples were similar in all parameters except the sodium content and therefore well suitable for the intended investigation of the impact of sodium ions on pectin gelation and degradation.
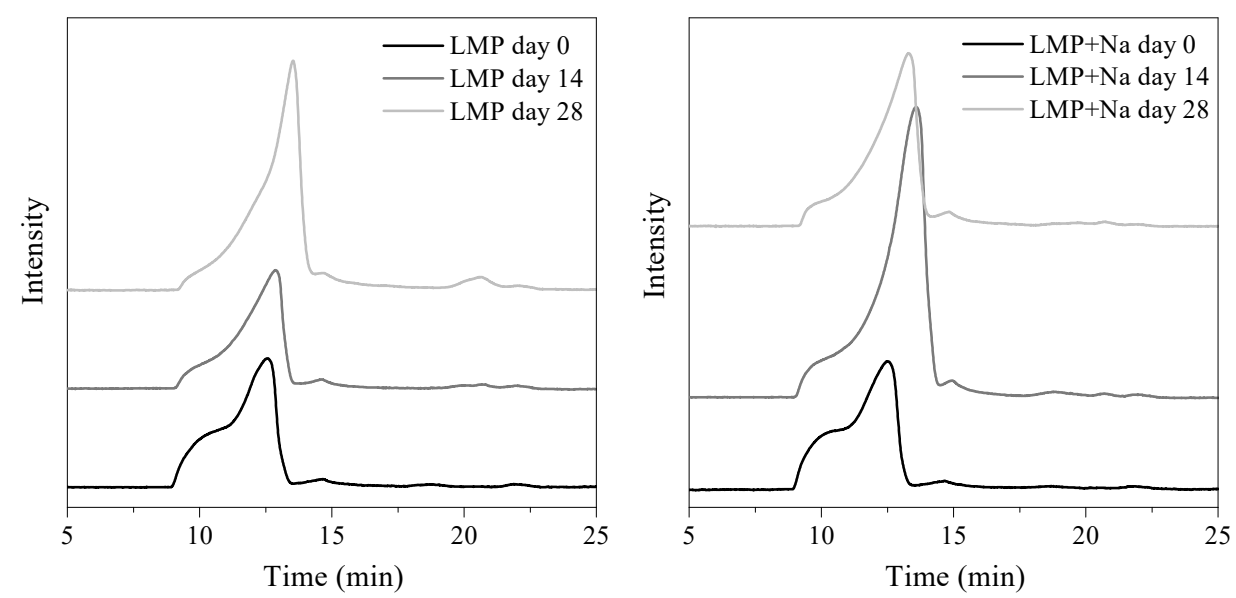

Fig. 3 GPC-images of the pectin samples before (day 0) and after (day 14 and 28) thermolysis.

\subsection{Impact of sodium ions on pectin material properties}

Enrichment with sodium had a marked influence on the material properties. Free carboxyl groups in solution of sodium-depleted pectin at low $\mathrm{pH}$ are mainly undissociated. As a consequence, pectin macromolecules may come in close contact and intermolecular hydrogen bonds may be formed. The compact molecular structure is trapped during drying and milling. The resulting particles were large, compact and smooth. During sodium ion loading at $\mathrm{pH} 11$, carboxyl groups are dissociated, and sodium ions associate strongly. They are hardly removable during the following preparation procedure. As a consequence, the number of hydrogen bonds formed in solution is reduced, and smaller and partly fibrous particles were formed after drying and milling as illustrated by SEM (Fig. 4).
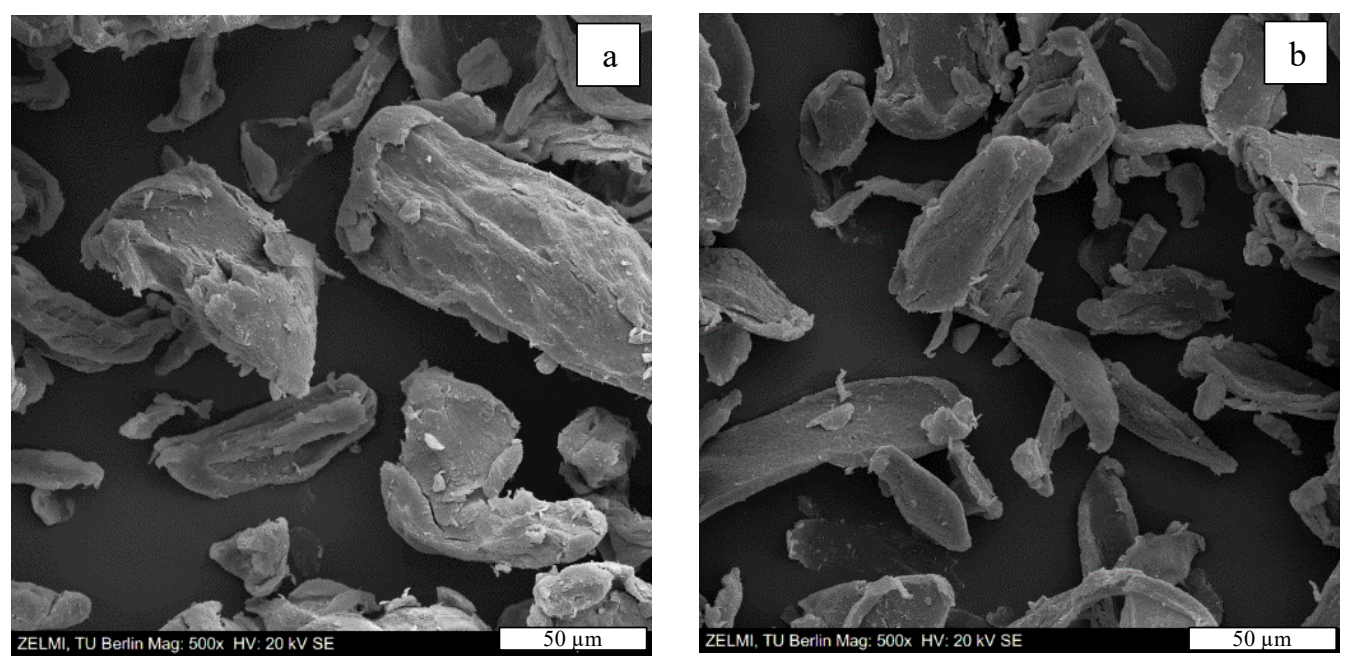

Fig. 4 SEM-images of pectin particles of the two samples. a: sodium-depleted (LMP) and b: sodium-enriched (LMP+Na) sample. 
Alterations of the pectin material properties after sodium ion enrichment was clearly reflected by differences in thermal analysis, in particular in the DSC curves (Fig. 5a). The thermogram of the acidic modified sample (AMP), used for the preparation of the two tested samples, and that of the sodiumdepleted sample (LMP) were very similar. Both showed a large endothermic peak, followed by a smaller exothermic pyrolysis peak. The endothermic peak reflects the enthalpic process of loosening intermolecular hydrogen bonds (Einhorn-Stoll \& Kunzek, 2009). Dissolution and precipitation for preparing LMP caused a slight reduction of this starting peak and increase of the pyrolysis peak. Obviously, the very compact structure of the AMP was not completely restored in the dried sodiumdepleted LMP due to a difference in $\mathrm{pH}$ in solution (1.5 for AMP and 2.5 for LMP). The difference in DSC of AMP and LMP was, however, marginal in comparison to the alterations observed in the sodium ion enriched sample. The endothermic starting peak completely vanished, and the exothermic pyrolysis peak was more intensified (Fig. 5a). The DTG-curve (Fig. 5b) also differed, they shifted to the left (range of lower temperature). This indicates that weight loss during pyrolysis started earlier. The alterations in DSC and DTG reflect the looser structure within the pectin particles of the LMP+Na. The curves of LMP and LMP+Na were comparable to those found before for pectin samples from acidic and alkaline modification, respectively (Einhorn-Stoll \& Kunzek, 2009).
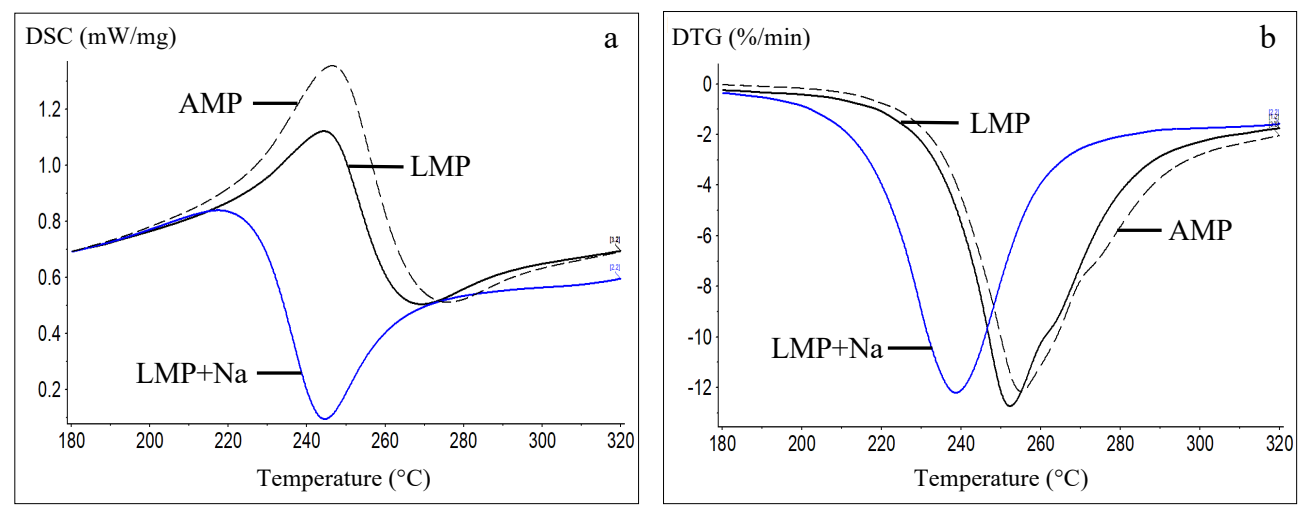

Fig. 5 Thermal analysis of the acidic modified pectin (AMP), sodium-depleted (LMP) and sodium-enriched (LMP+Na) sample. a: Differential scanning calorimetry (DSC) data and b: Differential thermogravimetry (DTG) data.

The two samples LMP and LMP+Na differed slightly in colour parameters a and $b$, the values were higher for LMP (Table 1). The small differences ( 0.3 for a-value and 1.8 for $b$-value) resulted from the differing particle structure, as shown in the SEM images (Fig. 4a, b). As discussed recently (EinhornStoll et al., 2019), less compact particles caused a higher reflection of light, and the LMP+Na appeared to be less intensively coloured. Additional evidence for the effect of sodium ion loading on the material properties of pectin is provided by the BET-surface. A higher BET-surface of LMP+Na $\left(1.44 \pm 0.00 \mathrm{~m}^{2} \mathrm{~g}^{-1}\right)$ was observed compared to LMP $\left(1.30 \pm 0.02 \mathrm{~m}^{2} \mathrm{~g}^{-1}\right)$. As a result of the higher particle surface, also the water uptake increased from $0.50 \pm 0.00 \mathrm{~g} \mathrm{~g}^{-1}$ (LMP) to $0.54 \pm 0.01 \mathrm{~g} \mathrm{~g}^{-1}$ $(\mathrm{LMP}+\mathrm{Na})$. Though only the difference of BET-surface between LMP and LMP+Na was obvious, the difference between LMP and LMP+Na in both parameters was large enough to prove the effect of sodium enrichment. 
Table 1 Alteration of molecular parameters and colour of the pectin samples during storage in the climate chamber at $60{ }^{\circ} \mathrm{C}$ and $80 \%$ relative humidity. DM: degree of methoxylation; [ $\eta$ ]: intrinsic viscosity; a-value / $b$-value: colour, determined by the CIELAB-system; $A_{235}$ : absorption at $235 \mathrm{~nm}$.

\begin{tabular}{|c|c|c|c|c|c|c|c|c|c|c|c|c|c|c|c|}
\hline Sample & $\mathrm{DM}(\%)$ & \pm & $\Delta \mathrm{DM}(\%)$ & {$[\eta]\left(\mathrm{cm}^{3} \mathrm{~g}^{-1}\right)$} & $\mathrm{SD}$ & $\Delta[\eta](\%)$ & a-value & $\mathrm{SD}$ & $\Delta$ a-value $(\%)$ & b-value & $\mathrm{SD}$ & $\Delta$ b-value (\%) & $\mathrm{A}_{235}$ & \pm & $\Delta \mathrm{A}(\%)$ \\
\hline \multicolumn{16}{|l|}{$L M P$} \\
\hline day 0 & 42.8 & 0.8 & 100 & 512 & 4.9 & 100 & 1.4 & 0.04 & 100 & 12.8 & 0.21 & 100 & 0.315 & 0.001 & 100 \\
\hline day 7 & 21.7 & 0.2 & 51 & 166 & 3.9 & 32 & 2.4 & 0.05 & 171 & 16.1 & 0.17 & 126 & n.a. & - & - \\
\hline day 14 & 9.3 & 0.1 & 22 & 94 & 2.7 & 18 & 3.3 & 0.04 & 236 & 18.5 & 0.07 & 145 & n.a. & - & - \\
\hline day 21 & 4.6 & 0.1 & 11 & 75 & 2.2 & 15 & 4.6 & 0.04 & 329 & 21.6 & 0.07 & 169 & n.a. & - & - \\
\hline day 28 & 3.1 & 0.2 & 7 & 63 & 1.5 & 12 & 5.8 & 0.05 & 414 & 23.9 & 0.11 & 187 & 0.519 & 0.015 & 165 \\
\hline \multicolumn{16}{|l|}{$L M P+N a$} \\
\hline day 0 & 41.4 & 0.1 & 100 & 519 & 3.1 & 100 & 1.1 & 0.06 & 100 & 11.0 & 0.16 & 100 & 0.281 & 0.001 & 100 \\
\hline day 7 & 31.9 & 0.3 & 77 & 275 & 1.2 & 53 & 2.7 & 0.05 & 245 & 16.9 & 0.16 & 154 & n.a. & - & - \\
\hline day 14 & 23.2 & 0.0 & 56 & 179 & 3.4 & 34 & 3.5 & 0.05 & 318 & 19.2 & 0.13 & 175 & n.a. & - & - \\
\hline day 21 & 15.4 & 0.1 & 37 & 125 & 1.9 & 24 & 4.8 & 0.09 & 436 & 22.0 & 0.43 & 200 & n.a. & - & - \\
\hline day 28 & 10.6 & 0.1 & 26 & 109 & 2.7 & 21 & 6.0 & 0.10 & 545 & 24.6 & 0.42 & 224 & 0.537 & 0.002 & 191 \\
\hline \multicolumn{16}{|l|}{$\pm:$ Range } \\
\hline \multicolumn{16}{|c|}{$\Delta:$ Value in $\%$ related to value before storage } \\
\hline \multicolumn{16}{|c|}{ SD: Standard deviation } \\
\hline n.a.: Not analys & & & & & & & & & & & & & & & \\
\hline
\end{tabular}

\subsection{Impact of sodium ion enrichment on pectin gelation}

The impact of sodium ion loading on the structuring properties was examined in a sugar-acid as well as in a sugar-calcium system, since the DM of the two samples (42.8\% for LMP and $41.4 \%$ for $\mathrm{LMP}+\mathrm{Na}$ ) allowed this variation. The sugar-acid system is used for testing cold-set gelation as typical for high-methoxylated pectin. The sugar-calcium system is applied for testing additional ionotropic gelation in LMP.

Table 2 Structuring temperatures of the sodium-depleted (LMP) and sodium-enriched (LMP+Na) pectin sample. IST: initial structuring temperature; GP: gel point; CST: critical structuring temperature.

\begin{tabular}{|c|c|c|c|}
\hline & IST $\left({ }^{\circ} \mathrm{C}\right)$ & $\operatorname{CST}\left({ }^{\circ} \mathrm{C}\right)$ & GP $\left({ }^{\circ} \mathrm{C}\right)$ \\
\hline \multicolumn{4}{|c|}{$\overline{\text { Sugar-acid system }}$} \\
\hline LMP & $59.3 \pm 0.9$ & $50.0 \pm 1.0$ & $56.2 \pm 0.9$ \\
\hline $\mathrm{LMP}+\mathrm{Na}$ & $59.1 \pm 1.5$ & $51.5 \pm 0.9$ & $54.8 \pm 0.9$ \\
\hline \multicolumn{4}{|c|}{ Sugar-calcium system } \\
\hline LMP & $37.0 \pm 3.4$ & $24.7 \pm 0.4$ & $19.0 \pm 0.2$ \\
\hline $\mathrm{LMP}+\mathrm{Na}$ & $39.9 \pm 2.1$ & $30.8 \pm 1.6$ & $27.5 \pm 1.6$ \\
\hline
\end{tabular}

Sodium ion enrichment retarded gelation in the sugar-acid system but accelerated structure formation in the sugar-calcium system due to the effect on intermolecular interactions. This was derived from the characteristic parameters IST, CST and GP, determined by temperature sweep measurements (Table 2). All values in the sugar-acid system were between 50 and $60{ }^{\circ} \mathrm{C}$, close to the $50{ }^{\circ} \mathrm{C}$ threshold marking the change of the junction zone type from hydrophobic interactions to hydrogen bonds (Lopes da Silva \& Rao, 2006; Thakur et al., 1997; Oakenfull \& Scott, 1984). CST and GP of the two samples slightly differed (Table 2). In addition, a difference in the structuring velocity curves (Fig. 6) reflected the impact of sodium ions on pectin gelation. The structuring velocity $\mathrm{dG}^{\prime} / \mathrm{dt}$ showed an earlier and stronger increase in the sodium-depleted pectin than in the sodium-enriched sample. Since the formation of hydrophobic interactions was similar for both samples and limited by the 
number of hydrophobic methoxyl groups at DM $42 \%$, the number of hydrogen bonds must be crucial for the difference. It was reduced due to interactions of sodium ions with some dissociated carboxyl groups, and the gelation process was slightly delayed.

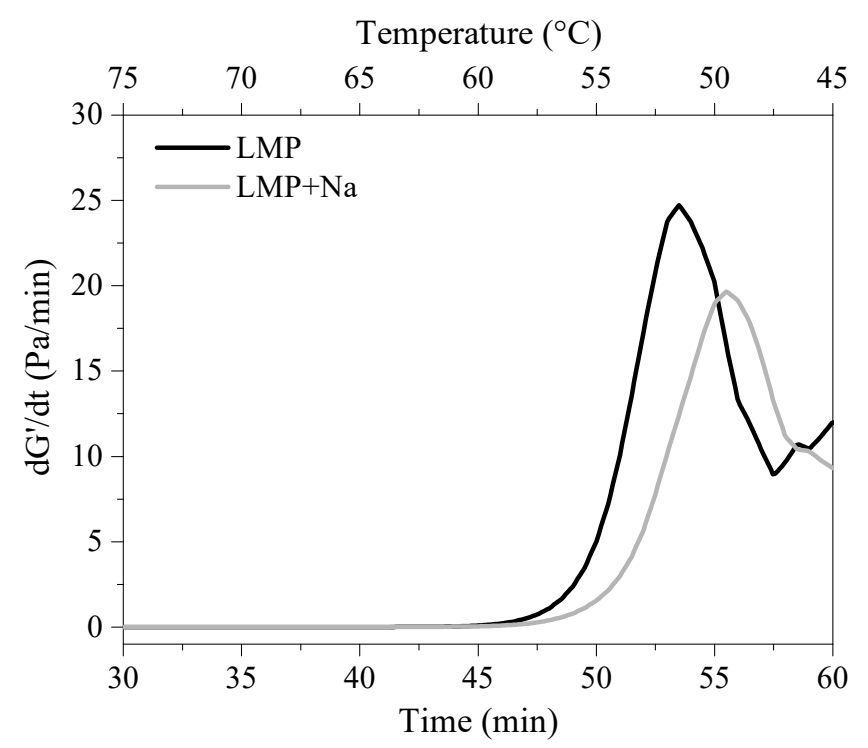

Fig. 6 Structuring velocity curve $\left(d G^{\prime} / d t\right)$ of the pectin samples in the sugar-acid system.

With respect to ionotropic gelation, it was assumed that sodium ions might bind to dissociated carboxyl groups, reduce ionotropic gelation via calcium bridges and delay the gelation of the sodiumenriched sample as described by Evageliou et al. (2019) for carrageenan or by Morris et al. (1982) for pectin. In contrast, the results of the temperature sweep measurements showed that the GP of the $\mathrm{LMP}+\mathrm{Na}$ was about $8.5 \mathrm{~K}$ and the CST of this sample was $6.1 \mathrm{~K}$ higher than the according structuring temperatures of the LMP (Table 2). The structuring velocity curves (Fig. 7) confirmed the differences by an earlier increase of the structuring velocity of LMP+Na. A similar result for the GP was found also in a previous work (Kastner et al., 2019), the GP of a sodium-enriched pectin of DM $41 \%$ was higher than that of a sodium-depleted sample of the same DM. Sodium ions probably bind to dissociated carboxyl groups, reduced the electrostatic repulsion by direct neutralisation and/or by preventing binding of calcium ions and allowed an early gelation by formation of junction zones of hydrogen bonds. This effect is comparable to the impact of the ionic strength on ionotropic gelation (Garnier et al., 1993) or to the effect of monovalent cations on the gelation of $\kappa$-carrageenan (Braudo, Muratalieva, Plashchina, Tolstoguzov, \& Markovich, 1991) and was described recently for pectincalcium-gels with low sodium ion concentration (John, Ray, Aswal, Deshpande, \& Varughese, 2019). Sodium ions bound to single dissociated carboxyl groups also decreased the possible binding of calcium ions to these groups by screening their charge (Axelos \& Thibault, 1991) or by a mixed counter-ion interaction (Lips et al., 1991), they reduced the possible unfavourable electrostatic as well as steric effects as described above. Additionally, a certain direct structuring effect of the sodium ions 
might have increased the GP, as described for the formation of weak gels in a calcium-free system at $\mathrm{pH} 3$ by Ström et al. (2014).

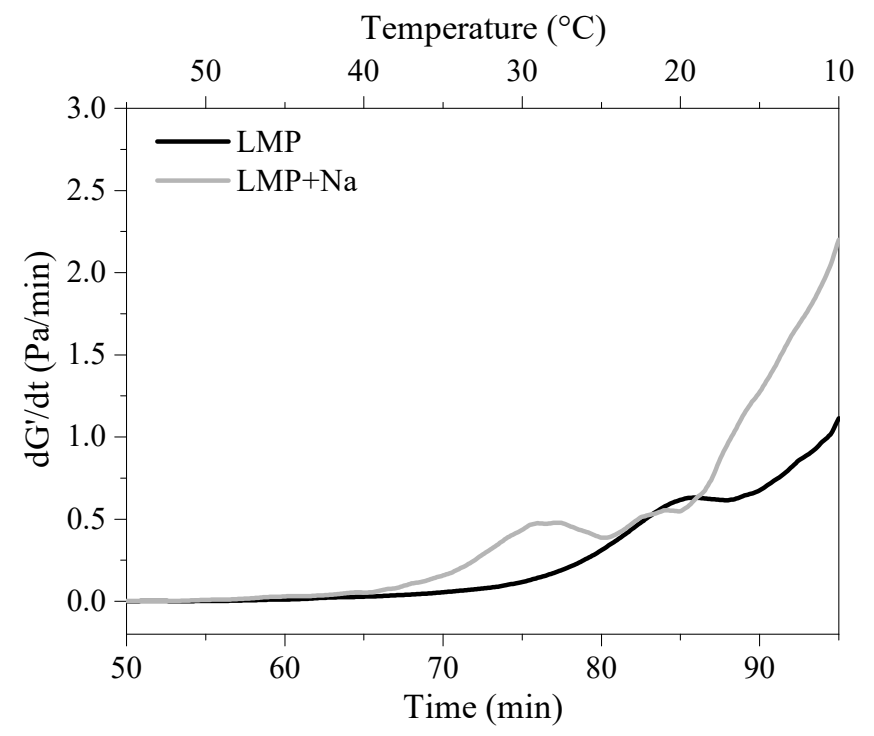

Fig. 7 Structuring velocity curve $\left(d G^{\prime} / d t\right)$ of the pectin samples in the sugar-calcium system.

\subsection{Impact of the addition of sodium ions on thermal degradation during storage}

There was strong evidence for a limiting effect of sodium ions on the thermal degradation of pectin by demethoxylation and depolymerisation during storage in our previous studies, but it was not finally proven. In the present study it is for the first time reported, that sodium ion loading reduces thermal degradation, i.e. increases the stability of pectin during storage.
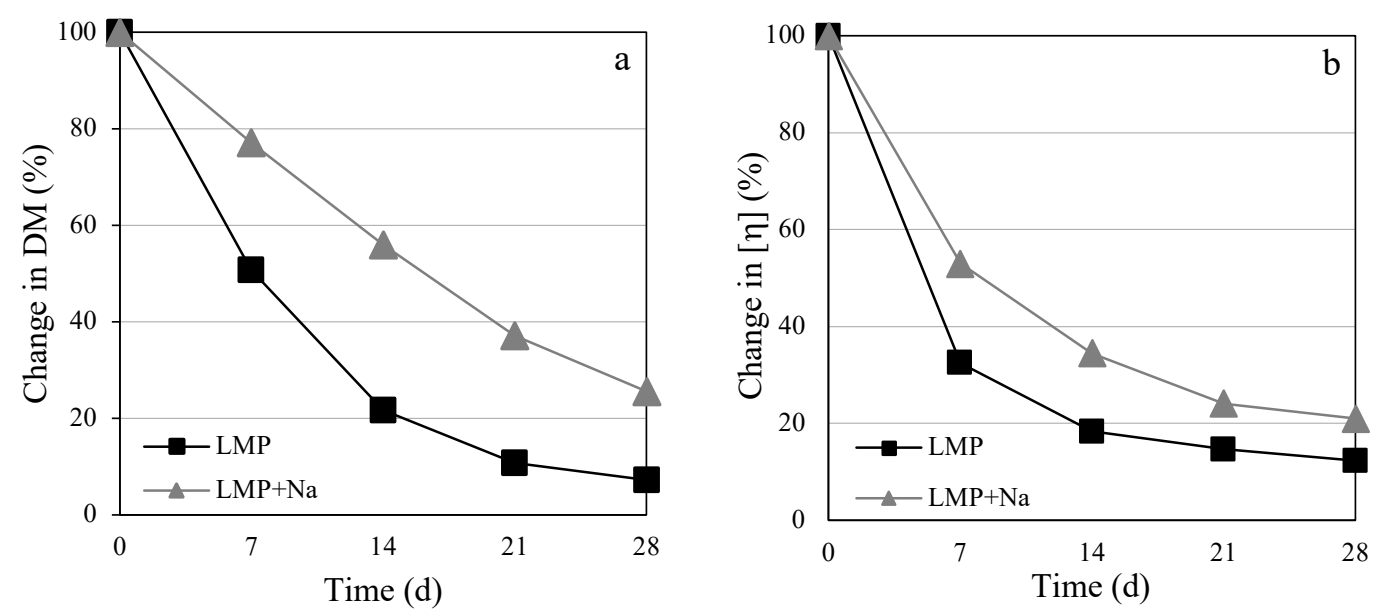

Fig. 8 Alteration of the molecular parameters in the course of thermolysis. a: degree of methoxylation (DM) and b: intrinsic viscosity [ $\eta$. 
The lower intensity of demethoxylation of LMP+Na in comparison to LMP (Table 1, Fig. 8a) was ascribed to a "protective" effect of sodium ions, which interacted with water (Deshpande et al., 2008) and reduced its availability for water-dependent demethoxylation. The inhibition of demethoxylation by sodium ion enrichment is reflected in thermal analysis. A shift of the DTG-curves (Fig. 9) as well as a corresponding shift of the DSC-signals (not shown) during storage, which is caused by demethoxylation (Einhorn-Stoll et al., 2009), was smaller for the LMP+Na than for LMP. The pyrolysis peak temperature difference within 28 days was $2.5 \mathrm{~K}$ for LMP+Na but $7.3 \mathrm{~K}$ for the LMP. In addition, signal reduction in ATR-FTIR at $1440 \mathrm{~cm}^{-1}$, representing methyl groups, was slightly lower for LMP+Na (Fig. 2b, c).
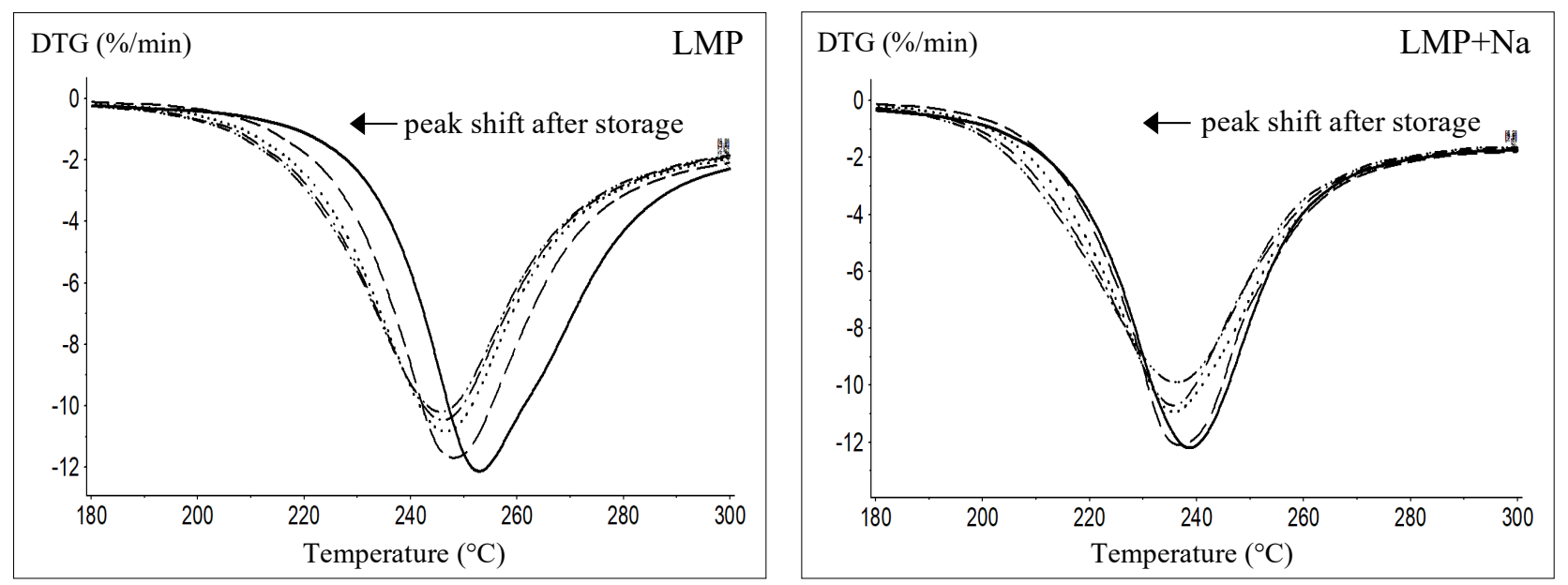

Fig. 9 DTG-curves of sodium-depleted (LMP) and sodium-enriched ( $L M P+N a)$ sample before and after thermolysis for 7, 14, 21 and 28 days.

A lower intensity of depolymerisation of $\mathrm{LMP}+\mathrm{Na}$ was concluded from a lower decrease of the intrinsic viscosity (Table 1, Fig. 8b), smaller alterations of the GPC-curves (Fig. 3) and by less pronounced signal changes in the ATR-FTIR spectra (Fig. 2). In GPC, depolymerisation of LMP and LMP+Na samples during storage caused a shift of the main peak (elution time 10-15 min) to the range of smaller molecules. This effect was already pronounced for both samples after 14 days but further increased until day 28 only in case of LMP. Moreover, only this sample formed a peak at elution time $20 \mathrm{~min}$, assigned to small molecules with molecular weight below $10 \mathrm{kD}$.

Major alterations in the ATR-FTIR signals (Fig. 2b, c) due to depolymerisation of the pectin samples were similar to those discussed more detailed in a corresponding paper (Einhorn-Stoll et al., 2020). The major effect, an increase of a signal at $950 \mathrm{~cm}^{-1}$ after thermal degradation, is ascribed to formation of rhamnogalacturonan I (Chylinska et al., 2016) by depolymerisation in the rhamnogalacturonan section of the pectin backbone. Signals at 830 and $785 \mathrm{~cm}^{-1}$ are typical for a $\mathrm{C}=\mathrm{C}$ stretch, and their increase indicated the formation of unsaturated components (oligogalacturonides - UOGA) as a result of depolymerisation. A more pronounced detection of galacturonic acid due to extended 
depolymerisation was represented by signals at 1015 up to $1100 \mathrm{~cm}^{-1}$ (Coimbra et al., 1998). All signal alterations were stronger in LMP than in $\mathrm{LMP}+\mathrm{Na}$, underlining the lower intensity of depolymerisation after sodium ion enrichment.

Pectin depolymerisation during storage is a complex process and so the explanation of the effect of the presence of sodium ions on this process is sophisticated. Two of the three reactions causing depolymerisation of pectin during storage, decarboxylation and backbone hydrolysis (Einhorn-Stoll et al., 2019) require free carboxyl groups $(-\mathrm{COOH})$ close to the cleaved glycosidic bonds. These groups are partly blocked in the $\mathrm{LMP}+\mathrm{Na}$ by sodium ions $(-\mathrm{COONa})$ and no more available for these reactions. Additional free carboxyl groups are formed by demethoxylation during storage and support depolymerisation. Due to a lower rate of demethoxylation, their number was lower in the LMP+Na than in LMP. The combination of reduction of the free carboxyl groups in the sample prior to storage (day 0 ) and a reduced formation of additional free carboxyl groups during storage resulted in a lower depolymerisation of the $\mathrm{LMP}+\mathrm{Na}$ by decarboxylation and backbone hydrolysis. Even though B-elimination was probably more pronounced during storage in LMP+Na than in LMP (due to the higher DM during storage), this reaction did not sufficiently compensate the limiting effect of sodium ions.

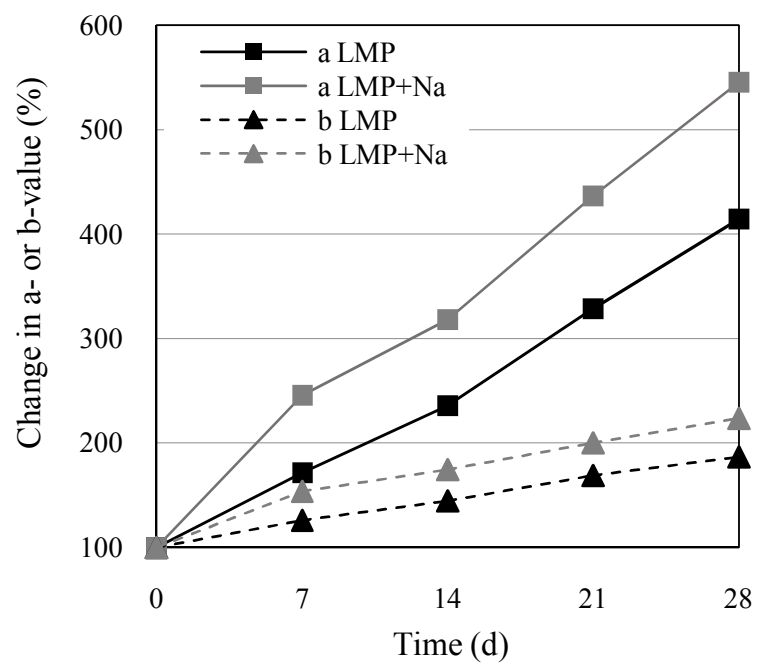

Fig. 10 Alteration of the colour of the sodium-depleted (LMP) and sodium-enriched (LMP+Na) sample in the course of thermolysis using the CIELAB system: a-value: red colour, b-value: yellow colour.

For distinction of the effect of sodium ion loading on decarboxylation and backbone hydrolysis, the browning intensity may be considered. Reaction products of pectin depolymerisation are unsaturated as well as saturated uronides (UOGA and sOGA) (Diaz, Anthon, \& Barrett, 2007). The uOGA are further degraded to coloured reaction products (Urbisch, Einhorn-Stoll, Kastner, Drusch, \& Kroh, 2018; Bornik \& Kroh, 2013), as shown in Fig. 10, and may be measured as browning by increasing a- and b-value. A difference in browning therefore may result from a different extent of depolymerisation by decarboxylation and/or ß-elimination, since depolymerisation by backbone hydrolysis mainly forms non-browning reducing uronides (Diaz et al., 2007). Browning during pectin 
storage may result also from degradation of neutral sugars (Einhorn-Stoll et al., 2019). This reaction should be, however, similar for the two samples, since their preparation procedures had no impact on the neutral sugar content and may be neglected. In the present study, LMP+Na developed a higher increase of a- and b-value during storage in comparison to LMP (Table 1, Fig. 10), though the overall depolymerisation in LMP was lower. This means that in LMP additional depolymerisation by backbone hydrolysis must have occurred, which decreased the molecular weight but did not contribute to browning. More insight is provided when evaluating results on the absorption at $235 \mathrm{~nm}\left(\mathrm{~A}_{235}\right)$ determined before and after storage (Table 1). This parameter illustrates the total content of uOGA in the samples, and its increase during storage gives information about the extent of depolymerisation by $ß$-elimination and decarboxylation. The increase of $A_{235}$ was lower for LMP $(165 \%)$ than for $\mathrm{LMP}+\mathrm{Na}(191 \%)$ and thus indicates a lower extent of uOGA-formation during storage in case of LMP, which is responsible for the lower extent of browning. So, it is concluded from the higher degree of depolymerisation, the less pronounced increase of $A_{235}$ and the lower extent of colour formation of $\mathrm{LMP}$ in comparison to LMP+Na, that a more pronounced backbone hydrolysis occurred in the sodiumdepleted pectin LMP.

In summary, the presence of sodium ions inhibited thermal degradation of dry pectin and increased, vice versa, the storage stability. Demethoxylation was directly affected by a reduction of the water available for this reaction through the sodium ions present. Depolymerisation was also affected by sodium ions, directly due to their association to free carboxyl groups, necessary for decarboxylation and backbone hydrolysis, and indirectly due to the more limited formation of additional free carboxyl groups via demethoxylation during storage. 


\section{Conclusions}

The preparation of two pectin samples with similar molecular parameters but different sodium ion content was achieved. The binding of the sodium ions and formation of a carboxylate structure was proved by ATR-FTIR spectroscopy. Examination of the two samples allowed a detailed evaluation of the impact of the presence of monovalent cations on pectin properties. The sodium ion content affected all parameters analysed in the present study and, thus, gains relevance in pectin application and shelf-life evaluation.

The content of monovalent cations in pectin varies, depending on the type of modification and corresponding conditions. Commercial pectin is mainly demethoxylated by acidic and enzymatic procedures. The sodium ion content is reduced by the acidic treatment but may be increased during enzymatic treatment. The impact of sodium ions on pectin gelation depends on the DM as well as on the gelation mechanisms. Sodium ions may delay structure formation during cold-set gelation in sugar-acid system by reducing the number of available hydrogen bonds. The structure formation in the sugar-calcium system, in contrast, may be accelerated by a reducing of electrostatic interactions. The impact on the ionotropic gelation will vary in dependence on the content of sodium and calcium ions, in particular in case of samples with DM between 40 and $50 \%$. Sodium-enriched pectin was less susceptible to thermal degradation than sodium-depleted pectin, in particular at high temperature and humidity. The blocking of free carboxyl groups by sodium ions reduces demethoxylation as well as depolymerisation by decarboxylation and backbone hydrolysis. In general, pectin suppliers as well as users should keep in mind, that the content of monovalent cations probably will affect pectin application. They might consider this knowledge in order to choose optimized modification procedures for preparing tailored pectin for special applications.

\section{Acknowledgements}

The authors are grateful for the financial support of the Deutsche Forschungsgemeinschaft (DFGproject Nr. DR 806/4-1 "Structure-depending degradation reactions of pectins and their impact on non-enzymatic browning and technological functionality"). They also would like to thank Christina Eichenauer for BET-surface measurement, Mario Harke for ATR-FTIR measurements and Andrea Krähmer for fruitful discussions of the ATR-FTIR results. 
List of abbreviations

AMP Pectin demethoxylated in acidic environment

ATR-FTIR Attenuated total reflection Fourier transform infrared spectroscopy

BET Brunauer-Emmett-Teller (method for calculating the surface of powder)

DM Degree of methoxylation

DSC Differential scanning calorimetry

DTG Differential thermogravimetry

GPC Gel permeation chromatography

LMP Low-methoxylated pectin, sodium-depleted sample

$\mathrm{LMP}+\mathrm{Na} \quad$ Low-methoxylated pectin, sodium-enriched sample

PME Pectinmethylesterases

SEM Scanning electron microscopy

sOGA Saturated galacturonides

TG Thermogravimetry

uOGA Unsaturated galacturonides

[ๆ] Intrinsic viscosity 


\section{References}

Axelos, M. A. V., Thibault, J. F. (1991). The chemistry of low-methoxyl pectin gelation. In R. H. Walter (Ed.), The Chemistry and Technology of Pectin (pp. 109-118). Academic Press. https://doi.org/10.1016/B978-0-08-092644-5.50011-X

Bäuerle, G., Otterbach, G., Grieschner, K., \& Baumann, G. (1977). Bestimmungen des Polyuronidgehaltes und des Veresterungsgrades des Pektinanteiles in Handelspektinpräparaten, Apfelsäften und Apfelmaceraten. Deutsche LebensmittelRundschau, 73, 281-286.

Bornik, M., \& Kroh, L. W. (2013). D-galacturonic acid as a highly reactive compound in nonenzymatic browning. 1. Formation of Browning Active Degradation Products. Journal of Agricultural and Food Chemistry, 61, 3494-3500. https://doi.org/10.1021/jf303855s

Braudo, E. E., Muratalieva, I. R., Plashchina, I. G., Tolstoguzov, V. B., \& Markovich, I. S. (1991). Studies on the mechanisms of gelation of kappa-carrageenan and agarose. Colloid \& Polymer Science, 269, 1148-1156. https://doi.org/10.1007/BF00654123

Chatjigakis, A., Pappas, C., Proxenia, N., Kalantzi, O., Rodis, P., \& Polissiou, M. (1998). FT-IR spectroscopic determination of the degree of esterification of cell wall pectins from stored peaches and correlation to textural changes. Carbohydrate Polymers, 37, 395-408. https://doi.org/10.1016/S0144-8617(98)00057-5

Chylinska, M., Szymanska-Chargot, M., \& Zdunek, A. (2016). FT-IR and FT-Raman characterization of non-cellulosic polysaccharides fractions isolated from plant cell wall. Carbohydrate Polymers, 154, 48-54. https://doi.org/10.1016/j.carbpol.2016.07.121

Coimbra, M. A., Barros, A., Barros, M., Rutledge, D., \& Delgadillo, I. (1998). Multivariate analysis of uronic acid and neutral sugars in whole pectic samples by FT-IR spectroscopy. Carbohydrate Polymers, 37, 241-248. https://doi.org/10.1016/S0144-8617(98)00066-6

Coimbra, M. A., Barros, A., Rutledge, D. N., \& Delgadillo, I. (1999). FTIR spectroscopy as a tool for the analysis of olive pulp cell-wall polysaccharide extracts. Carbohydrate Research, 317, 145154. https://doi.org/10.1016/S0008-6215(99)00071-3

Deshpande, M. D., Scheicher, R. H., Ahuja, R., \& Pandey, R. (2008). Binding strength of sodium ions in cellulose for different water contents. Journal of Physical Chemistry B, 112, 8985-8989. https://doi.org/10.1021/jp8020547

Diaz, J. V., Anthon, G. E., \& Barrett, D. M. (2007). Nonenzymatic degradation of citrus pectin and pectate during prolonged heating: Effects of $\mathrm{pH}$, temperature, and degree of methyl esterification. Journal of Agricultural and Food Chemistry, 55, 5131-5136. 
https://doi.org/10.1021/jf0701483

Einhorn-Stoll, U., Vasileva, E., Hecht, T., \& Drusch, S. (2016). Investigation of pectin-water interactions: A practical approach. In P. A. Williams \& G. O. Phillips (Eds.), Gums and Stabilisers for the Food Industry 18 - Hydrocolloid Functionality for Affordable and Sustainable Global Food Solutions (pp. 1-12). https://doi.org/10.1039/9781782623830-00001

Einhorn-Stoll, U., Hatakeyama, H., \& Hatakeyama, T. (2012). Influence of pectin modification on water binding properties. Food Hydrocolloids, 27, 494-502.

https://doi.org/10.1016/j.foodhyd.2011.08.019

Einhorn-Stoll, U., Kastner, H., Urbisch, A., Kroh, L. W., \& Drusch, S. (2019). Thermal degradation of citrus pectin in low-moisture environment - Influence of acidic and alkaline pre-treatment. Food Hydrocolloids, 86, 104-115. https://doi.org/10.1016/j.foodhyd.2018.02.030

Einhorn-Stoll, U., Kastner, H., Fatouros, A., Krähmer, A., Kroh, L. W., \& Drusch, S. (2020). Thermal degradation of citrus pectin in low-moisture environment - Investigation of backbone depolymerisation. Food Hydrocolloids, submitted.

Einhorn-Stoll, U., \& Kunzek, H. (2009). Thermoanalytical characterisation of processing-dependent structural changes and state transitions of citrus pectin. Food Hydrocolloids, 23, 40-52. https://doi.org/10.1016/j.foodhyd.2007.11.009

Endress, H. U, Christensen, S. H. (2009). Pectins. In P. A. Phillips, G. O., Williams (Eds.), Handbook of Hydrocolloids (Second Edition) (pp. 274-297). Woodhead Publishing. https://doi.org/10.1533/9781845695873.274.

Evageliou, V. I., Ryan, P. M., \& Morris, E. R. (2019). Effect of monovalent cations on calciuminduced assemblies of kappa carrageenan. Food Hydrocolloids, 86, 141-145.

https://doi.org/10.1016/j.foodhyd.2018.03.018

Fellah, A., Anjukandi, P., Waterland, M. R., \& Williams, M. A. K. (2009). Determining the degree of methylesterification of pectin by ATR/FT-IR: Methodology optimisation and comparison with theoretical calculations. Carbohydrate Polymers, 78, 847-853.

https://doi.org/10.1016/j.carbpol.2009.07.003

Fraeye, I., Duvetter, T., Doungla, E., Van Loey, A., \& Hendrickx, M. (2010). Fine-tuning the properties of pectin-calcium gels by control of pectin fine structure, gel composition and environmental conditions. Trends in Food Science and Technology, 21, 219-228. https://doi.org/10.1016/j.tifs.2010.02.001

Gao, Z., Fang, Y., Cao, Y., Liao, H., Nishinari, K., \& Phillips, G. O. (2017). Hydrocolloid-food component interactions. Food Hydrocolloids, 68, 149-156. 
https://doi.org/10.1016/j.foodhyd.2016.08.042

Garnier, C., Axelos, M. A. V., \& Thibault, J. F. (1993). Phase diagrams of pectin-calcium systems: Influence of $\mathrm{pH}$, ionic strength, and temperature on the gelation of pectins with different degrees of methylation. Carbohydrate Research, 240, 219-232. https://doi.org/10.1016/00086215(93)84185-9

Hotchkiss, A. T., Savary, B. J., Cameron, R. G., Chau, H. K., Brouillette, J., Luzio, G. A., \& Fishman, M. L. (2002). Enzymatic modification of pectin to increase its calcium sensitivity while preserving its molecular weight. Journal of Agricultural and Food Chemistry, 50, 2931-2937. https://doi.org/10.1021/jf011187w

John, J., Ray, D., Aswal, V. K., Deshpande, A. P., \& Varughese, S. (2019). Dissipation and strainstiffening behavior of pectin-Ca gels under LAOS. Soft Matter, 15, 6852-6866. https://doi.org/10.1039/c9sm00709a

Kačuráková, M., Capek, P., Sasinkova, V., Wellner, N., Ebringerova, A., \& Kac, M. (2000). FT-IR study of plant cell wall model compounds: pectic polysaccharides and hemicelluloses. Carbohydrate Polymers, 43, 195-203. https://doi.org/10.1016/S0144-8617(00)00151-X

Kalathaki, I., Alba, K., Muhamedsalih, H., \& Kontogiorgos, V. (2019). Fabrication and characterisation of metal-doped pectin films. Food Hydrocolloids, 92, 259-266. https://doi.org/10.1016/j.foodhyd.2019.01.065

Kastner, H., Einhorn-Stoll, U., \& Drusch, S. (2019). Influence of enzymatic and acidic demethoxylation on structure formation in sugar containing citrus pectin gels. Food Hydrocolloids, 89, 207-215. https://doi.org/10.1016/j.foodhyd.2018.10.031

Kastner, H., Einhorn-Stoll, U., \& Senge, B. (2012). New parameters for the examination of the pectin gelation process. In P. A. Williams \& G. O. Phillips (Eds.), Gums and Stabilisers for the Food Industry 16 (pp. 190-198). Cambridge: RSC Publishing. https://doi.org/10.1039/9781849734554-00191

Liners, F., Thibault, J.-F., \& Van Cutsem, P. (1992). Influence of the degree of polymerization of oligogalacturonates and of esterification pattern of pectin on their recognition by monoclonal antibodies. Plant Physiology, 99, 1099-1104. https://doi.org/10.1104/pp.99.3.1099

Lips, A., Clark, A. H., Cutler, N., \& Durand, D. (1991). Measurement of cooperativity of binding of calcium to neutral sodium pectate. Topics in Catalysis, 5, 87-99.

https://doi.org/10.1016/S0268-005X(09)80291-9

Lopes da Silva, J. A., Rao, M. A. (2006). Pectins: Structure, functionality, and uses. In A. M. Stephen, G. O. Phillips, P. A. Williams (Eds.), Food Polysaccharides and Their Applications 
(pp. 353-411). Taylor \& Francis. https://doi.org/10.1201/9781420015164

Luzio, G. A., \& Cameron, R. G. (2008). Demethylation of a model homogalacturonan with the saltindependent pectin methylesterase from citrus: Part II. Structure-function analysis. Carbohydrate Polymers, 71, 300-309. https://doi.org/10.1016/j.carbpol.2007.05.038

Manrique, G. D., \& Lajolo, F. M. (2002). FT-IR spectroscopy as a tool for measuring degree of methyl esterification in pectins isolated from ripening papaya fruit, Postharvest Biology and Technology, 25, 99-107. https://doi.org/10.1016/S0925-5214(01)00160-0

Marudova, M., \& Jilov, N. (2003). Influence of sodium citrate and potassium-sodium tartrate on gelation of low-methoxyl amidated pectin. Journal of Food Engineering, 59, 177-180. https://doi.org/10.1016/S0260-8774(02)00455-7

Morris, E. R., Powell, D. A, Gidley, M. J., \& Rees, D. A. (1982). Conformations and interactions of pectins. I. Polymorphism between gel and solid states of calcium polygalacturonate. Journal of Molecular Biology, 155, 507-516. http://dx.doi.org/10.1016/0022-2836(82)90484-3

Ngouémazong, D. E., Kabuye, G., Fraeye, I., Cardinaels, R., Van Loey, A., Moldenaers, P., \& Hendrickx, M. (2012). Effect of debranching on the rheological properties of $\mathrm{Ca}^{2+}$-pectin gels. Food Hydrocolloids, 26, 44-53. https://doi.org/10.1016/j.foodhyd.2011.04.009

Oakenfull, D., \& Scott, A. (1984). Hydrophobic interaction in the gelation of high methoxyl pectins. Food Science, 49, 1093-1098. https://doi.org/10.1111/j.1365-2621.1984.tb10401.x

Powell, D. A, Morris, E. R., Gidley, M. J., \& Rees, D. A. (1982). Conformations and interactions of pectins. II. Influences of residue sequence on chain association in calcium pectate gels. Journal of Molecular Biology, 155, 517-531. https://doi.org/10.1016/0022-2836(82)90485-5

Ralet, M. C., Dronnet, V., Buchholt, H. C., \& Thibault, J. F. (2001). Enzymatically and chemically deesterified lime pectins: Characterisation, polyelectrolyte behaviour and calcium binding properties. Carbohydrate Research, 336, 117-125. https://doi.org/10.1016/S00086215(01)00248-8

Rees, D. A. (1982). Polysaccharide conformation in solutions and gels - Recent results on pectins. Carbohydrate Polymers, 2, 254-263. https://doi.org/10.3109/03009737709179075

Rolin, C., Chrestensen, I. B., Hansen, K. M., Staunstrup, J., \& Sørensen, S. (2010). Tailoring pectin with specific shape, composition and esterification pattern. In P. A. Williams \& G. O. Phillips (Eds.), Gums and Stabilisers for the Food Industry 15 (pp. 13-25). Cambridge: RSC Publishing. https://doi.org 10.1039/9781849730747-00013

Sousa, A. G., Nielsen, H. L., Armagan, I., Larsen, J., \& Sørensen, S. O. (2015). The impact of rhamnogalacturonan-I side chain monosaccharides on the rheological properties of citrus 
pectin. Food Hydrocolloids, 47, 130-139. https://doi.org/10.1016/j.foodhyd.2015.01.013

Ström, A., Schuster, E., \& Goh, S. M. (2014). Rheological characterization of acid pectin samples in the absence and presence of monovalent ions. Carbohydrate Polymers, 113, 336-343. https://doi.org/10.1016/j.carbpol.2014.06.090

Thakur, B. R., Singh, R. K., \& Handa, A. K. (1997). Chemistry and uses of pectin--a review. Critical Reviews in Food Science and Nutrition, 37, 47-73. https://doi.org/10.1080/10408399709527767

Urbisch, A., Einhorn-Stoll, U., Kastner, H., Drusch, S., \& Kroh, L. W. (2018). Formation of phenolic compounds from D-galacturonic acid, Journal of Agricultural and Food Chemistry, 66, 11407 11413. https://doi.org/10.1021/acs.jafc.8b04158

Vincent, R. R., \& Williams, M. A. K. (2009). Microrheological investigations give insights into the microstructure and functionality of pectin gels, Carbohydrate Research, 344, 1863-1871. https://doi.org/10.1016/j.carres.2008.11.021

Voragen, A. G. J., Coenen, G.-J., Verhoef, R. P. \& Schols, H. A. (2009). Pectin, a versatile polysaccharide present in plant cell walls. Structural Chemistry, 20, 263275. https://doi.org/10.1007/s11224-009-9442-z

Wang, H., Wan, L., Chen, D., Guo, X., Liu, F., \& Pan, S. (2019). Unexpected gelation behavior of citrus pectin induced by monovalent cations under alkaline conditions. Carbohydrate Polymers, 212, 51-58. https://doi.org/10.1016/j.carbpol.2019.02.012

Wang, K., Hua, X., Yang, R., Kang, J., \& Zhang, W. (2014). Hydrodynamic behavior and gelling properties of sunflower head pectin in the presence of sodium salts. Food Hydrocolloids, 36, 238-244. https://doi.org/10.1016/j.foodhyd.2013.09.011

Wegener, S., Kaufmann, M., \& Kroh, L. W. (2017). Influence of L-pyroglutamic acid on the color formation process of non-enzymatic browning reactions. Food Chemistry, 232, 450-454. https://doi.org/10.1016/j.foodchem.2017.04.046

Wehr, J. B., Menzies, N. W., \& Blamey, F. P. C. (2004). Alkali hydroxide-induced gelation of pectin. Food Hydrocolloids, 18, 375-378. https://doi.org/10.1016/S0268-005X(03)00124-3

Yoo, S. H., Lee, B. H., Savary, B. J., Lee, S., Lee, H. G., \& Hotchkiss, A. T. (2009). Characteristics of enzymatically-deesterified pectin gels produced in the presence of monovalent ionic salts. Food Hydrocolloids, 23, 1926-1929. https://doi.org/10.1016/j.foodhyd.2009.02.006 